\title{
ESTIMASI STOK KARBON MENGGUNAKAN SPEKTRAL BAND 6 CITRA LANDSAT 8 PADA KAWASAN MANGROVE DI SUNGAI TALLO, KOTA MAKASSAR SULAWESI SELATAN TAHUN 2018
}

\author{
Agung Sandi Budiman ${ }^{*}$ \\ ${ }^{1}$ Geofisika dan Meteorologi, Fakultas Matematika dan Ilmu Pengetahuan Alam, Institut Pertanian Bogor, \\ Bogor \\ ${ }^{*}$ E-mail: agungsandi39@gmail.com
}

\begin{abstract}
ABSTRAK
Kota Makassar merupakan salah satu kota dataran rendah di Indonesia dengan ketinggian yang bervariasi antara 1-25 meter di atas permukaan laut yang banyak ditumbuhi oleh tanaman mangrove di salah satu sungai nya yaitu Sungai Tallo. Tanaman mangrove yang tumbuh didaerah tersebut dapat dipergunakan untuk menduga nilai estimasi stok karbon melalui biomassanya, namun hal ini masih belum banyak dilakukan lantaran lokasinya yang jauh terutama untuk para peneliti dari luar Kota Makassar sehingga dana yang diperlukan untuk melakukan pengamatan langsung ini pun menjadi lebih besar. Oleh sebab itu penelitian ini dilakukan dengan maksud memanfaatkan Sistem Informasi Geografi dan citra Landsat 8 untuk dapat mengetahui nilai estimasi stok karbon menggunakan spectral band 6 citra satelit Landsat 8 dengan biomassa pada kawasan mangrove di Sungai Tallo Kota Makassar Sulawesi Selatan pada tahun 2018 tanpa perlu datang ke lokasi nya langsung. Data yang digunakan dalam penelitian ini meliputi citra satelit Landsat 8 Kota Makassar yang diperoleh dari website earthexplorer.usgs.gov, data tutupan lahan tahun 2016, dan data shp wilayah Kota Makassar. Nilai estmasi potensi biomassa didapat dengan persamaan hasil regresi di kawasan mangrove di Sungai Tallo Makassar dengan nilai maksimumnya sebesar 1115.40 ton/ha dan nilai minimumnya 168.65 ton/ha dengan nilai estimasi stok karbon diperoleh dari 46\% dari biomassa sehingga diperolehlah nilai estimasi stok karbon maksimumnya sebesar 513.08 ton/ha dan minimumnya sebesar 77.57 ton/ha.
\end{abstract}

Kata kunci: biomassa, Landsat 8, stok karbon, Kota Makassar.

\begin{abstract}
Makassar City is one of the lowland cities in Indonesia with a height that varies between 1-25 meters above sea level which is overgrown by mangroves in one of its rivers, the Tallo River. Mangroves plants that grow in the area can be used to estimate the carbon stock through biomass, but this is still not done much because of its remote location, especially for researchers from outside the city of Makassar so that the funds needed to make direct observations are even bigger. Therefore this research was conducted with the intention of ultilizing the Geographic Information System and Landsat 8 imagery to be able to determinate the estimated of carbon stock value using spectral band 6 Landsat 8 satellite imagery with biomass in the mangrove ares on the Tallo River, Makassar City, South Sulawesi in 2018 without coming to location directly. The data used in this study included the Landsat 8 Makassar City satellite imagery obtained from the earthexplorer.usgs.gov website, 2016 land cover data, and Makassar City data shp. Estimation of biomass potential is obtained by the regression equation in the mangrove area of Tallo Makassar River with a maximum value of 1115.40 tons/ha and a minimum value of 168.65 tons/ha with estimated carbon stock obtained from $46 \%$ of biomass so that the maximum carbon stock estimation value is 513.08 tons/ha and the minimum is 77.57 tons/ha.
\end{abstract}

Keywords: biomass, carbon stock, Landsat 8, Makassar City. 


\section{PENDAHULUAN}

Kota Makassar merupakan salah satu kota dataran rendah dengan ketinggian yang bervariasi antara 1-25 meter di atas permukaan laut dengan luas wilayah Kota Makassar tercatat $175,77 \mathrm{~km}$ persegi yang meliputi 15 kecamatan, yang terletak di antara 119'24'17'38" Bujur Timur dan5'8'6'19" Lintang Selatan. Berdasarkan posisi geografisnya, Kota Makassar memiliki batasbatas: Utara yaitu Kabupaten Maros; Selatan yaitu Kabupaten Gowa; Barat yaitu Selat Makassar; Timur yaitu Kabupaten Maros (Badan Pusat Satistik, 2018).

Ekosistem mangrove (bakau) adalah ekosistem yang berada di daerah tepi pantai yang dipengaruhi oleh pasang surut air laut sehingga lantainya selalu tergenang air. Ekosistem mangrove berada di antara level pasang naik tertinggi sampai level di sekitar atau di atas permukaan laut rata-rata pada daerah pantai yang terlindungi (Supriharyono, 2007) dan menjadi pendukung berbagai jasa ekosistem di sepanjang garis pantai di kawasan tropis (Donato dkk., 2012). Jenis mangrove yang tumbuh di Indonesia sebanyak 38 spesies, diantaranya dari marga Rhizophora, Bruguiera, Avicennia, Sonneratia, Xylocarpus, Barringtonia, Luminitzera, Ceriops, dan Nypa Makassar memiliki Sungai Tallo yang merupakan habitat ekosistem mangrove. Beddu (2011) melaporkan bahwa Sungai Tallo dikelilingi oleh vegetasi mangrove yang beragam, terutama didominasi jenis Nypa, Avicennia, dan Rhizophora (Supriharyono, 2000).

Karbon merupakan salah satu unsur alam yang memiliki lambang " $\mathrm{C}$ " dengan nilai atom sebesar 12. Karbon juga merupakan salah satu unsur utama pembentuk bahan organik termasuk makhluk hidup. Hampir setengah dari organisme hidup merupakan karbon. Karenanya secara alami karbon banyak tersimpan di bumi (darat dan laut) dari pada di atmosfir. Perairan pesisir, termasuk mangrove, berperan penting terhadap total budget karbon (Nasprianto dkk., 2016). Tegakan mangrove, melalui proses fotosintesis menyerap karbon dioksida dari atmosfer yang diubahnya menjadi karbon organic dalam bentuk biomassa (Sutaryo, 2009).
Makalah ini dibuat dengan memanfaatkan Sistem Informasi Geografi dan citra Landsat 8 dengan tujuan dapat mengetahui nilai estimasi stok karbon menggunakan spectral band 6 citra satelit Landsat 8 dengan biomassa pada kawasan mangrove di Sungai Tallo Kota Makassar Sulawesi Selatan pada tahun 2018.

\section{METODE}

\subsection{Lokasi Kajian}

Data yang digunakan mengambil wilayah kajian di Kota Makassar yang merupakan kota internasional serta terbesar di kawasan Indonesia Timur dan pada masa lalu pernah menjadi ibu kota Negara Indonesia Timur Provinsi Sulawesi yang secara administrative terdiri dari 15 kecamatan dan terletak di antara 119'24'17'38' Bujur Timur dan5'8'6'19" Lintang Selatan (Badan Pusat Statistik, 2018).

\subsection{Alat dan Bahan}

Alat yang digunakan dalam penelitian ini adalah laptop yang sudah terinstal Microsoft Office 2007, aplikasi peramban internet, dan ArcGIS 10.3. Bahan penelitian yang digunakan adalah data citra satelit Landsat-8 band 6 di daerah Kota Makassar yang diperoleh dari website earthexplorer.usgs.gov, data sebaran tutupan lahan tahun 2016, dan jurnal mengenai lokasi/posisi mangrove di Sungai Tallo Kota Makassar.

\subsection{Tahap Penelitian}

Proyek penelititan ini dilakukan dengan tiga tahapan, yaitu input, analisis, dan output. Tahap input meliputi proses memasukkan data citra satelit Landsat- 8 Band 6 dan data tutupan lahan tahun 2016. Tahap analisis meliputi tahapan penentuan lokasi mangrove, deliniasi shp wilayah Kota Makassar, pengonversian digital number menjadi spektral radian, perhitungan nilai biomassa menggunakan hasil korelasi dan $\mathrm{R}^{2}$ pada band 6 Landsat 8, dan penentuan nilai stok karbon. Sedangkan tahap output merupakan tahap layouting peta.

\subsubsection{Penentuan Lokasi Mangrove}

Penentuan lokasi mangrove yang di hitung estimasi stok karbonnya berdasarkan penelititan yang dilakukan oleh Rahman dkk. ${ }^{8}$ 
yaitu berada di titik pengamatan 1 berdasarkan gambar 1 dibawah.

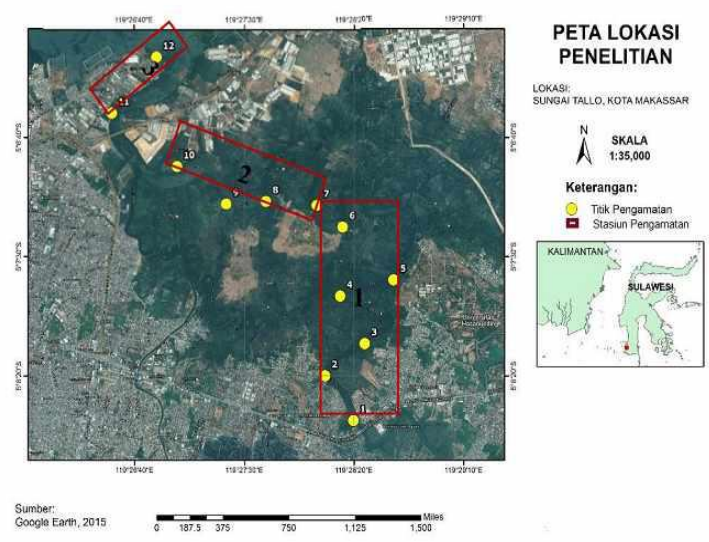

Gambar 1. Lokasi penelitian dan titik pengamatan.

sumber: Peta persebaran mangrove dalam studi Rahman (Rahman dan Rusmana, 2017).

\subsubsection{Deliniasi SHP Wilayah Mangrove Kota Makassar}

Proses deliniasi wilayah mangrove Kota Makassar ini dilakukan pada software ArcGIS dengan cara memotong hanya wilayah mangrove yang akan dihitung nilai biomassanya saja.

\subsubsection{Pengonversian Digital Number Menjadi Spektral Radian}

Perhitungan nilai spektral radian perlu dilakukan karena data citra satelit yang diunduh masih berupa data digital number (raw) sehingga perlu dilakukan konversi ke nilai spektral radian. Perhitungan nilai spektral dapat dilakukan dengan rumus USGS (2013) :

$L \lambda=\left(\frac{L M A X-L M I N}{\text { Qcalmax }-Q \text { calmin }}\right)(Q c a l-Q$ calmax $)+$

Lmax

Keterangan :

$\mathrm{L} \lambda=$ Spektral radian pada kanal ke i $\left(\mathrm{Wm}^{-2} \operatorname{str}^{-1} \mu \mathrm{m}^{-1}\right)$

Qcal $=$ Nilai digital number kanal ke-i

LMIN = Nilai minimum spectral radiance kanal ke-i

LMAX = Nilai maksimum spectral radiance kanal ke-i

Qcalmin = Minimum pixel value

Qcalmax = Maksimum pixel value (255)

\subsubsection{Perhitungan Nilai Biomassa Dengan Hasil Korelasi dan $\mathbf{R}^{2}$ Pada Band 6 Landsat 8}

Setelah mengetahui nilai spektral radian pada kanal ke I selanjutnya dilakukan penentuan persamaan regresi dan korelasi yang digunakan untuk dapat mendekati nilai dari biomassa yang ingin di ketahui dengan melihat tabel 1 dibawah. Berdasarkan tabel 1 tersebut persamaan regresi dan korelasi yang digunakan yaitu persamaan yang berada di band 6 yaitu persamaan $Y=2433 \exp ^{-0.377 X}$ (Utomo, 2015).

Tabel 1. Hasil korelasi dan $\mathrm{R}^{2}$ setiap band Landasat 8 dengan persamaannya.

\begin{tabular}{lcl}
\hline Band & Persamaan & $\mathbf{R}^{\mathbf{2}}$ \\
\hline 1 & $Y=1 \times 10^{10} \exp ^{-0.32 X}$ & $22 \%$ \\
2 & $Y=327656 \exp ^{-0.177 X}$ & $23 \%$ \\
3 & $Y=3567 \exp ^{-0.163 X}$ & $29 \%$ \\
4 & $Y=559.02 \exp ^{-0.109 X}$ & $23 \%$ \\
5 & $Y=0.1867 \exp ^{0.0687 X}$ & $12 \%$ \\
6 & $Y=2433 \exp ^{-0.377 X}$ & $62 \%$ \\
7 & $Y=5709 \exp ^{-0.124 X}$ & $62 \%$ \\
8 & $Y=91.964 \exp ^{-0.023 X}$ & $3 \%$ \\
9 & $Y=152.28 \exp ^{-10.41 X}$ & $1 \%$ \\
10 & $Y=1 \times 10^{25} \exp ^{-0.578 X}$ & $31 \%$ \\
11 & $Y=3 x 10^{20} \exp ^{-0.514 X}$ & $17 \%$ \\
NDVI & $Y=1.3515 \exp ^{6.2531 X}$ & $24 \%$ \\
\hline
\end{tabular}

Sumber data : Nilai biomassa hasil survei yang diregresikan dengan spectral setiap kanal dan NDVI Landsat 8 (Utomo, 2015).

\subsubsection{Penentuan Nilai Stok Karbon}

Setelah diketahui nilai dari biomassa menggunakan tabel persamaan regresi dan korelasi kemudian nilai dari biomassa itu digunakan untuk menduga nilai dari stok karbon dengan cara mengalikan nilai biomassa itu dengan 0.46 (Hairiah dan Rahayu, 2007).

\section{HASIL DAN PEMBAHASAN}

Penentuan nilai estimasi stok karbon yang ada pada kawasan mangrove di Sungai Tallo Makassar didapat dari nilai biomassa yang ada di kawasan mangrove tersebut. Menurut Hariah dan Rahayu (2007) estimasi nilai stok karbon ini didapat dari $46 \%$ dari hasil biomassanya. Pendugaan estimasi ini biasa dilakukan dengan mendatangi langsung daerah atau lokasi mangrove yang ingin diketahui nilai biomassa. Hal ini dikarenakan untuk menduga informasi kandungan 
biomassa diperoleh dari persamaan alometrik yang telah dikembangkan oleh Fromard dkk. (1998) dan Komiyama dkk. (2005) untuk tipe vegetasi tegakan pohon setelah dilakukan pengukuran diameter batang setinggi dada. Mangrove tipe palem seperti jenis Nypa yang belum diketahui persamaan alometrik untuk menghitung biomassanya dilakukan pengukuran biomassa dengan menebang mangrove pada range diameter (pangkal dan pelepah) dari terkecil hingga yang terbesar sekitar 10-15 pohon dengan terlebih dahulu melakukan pengukuran terhadap berat basah, berat kering, dan massa jenis mangrove. Secara umum nilai biomassa setiap spesies mangrove berbeda dan dipengaruhi oleh kemampuan sekuestrasi yang dapat dianalisis berdasarkan nilai massa jenis, diameter pohon ataupun ketinggiannya (Rahman dan Rusmana, 2017).

Penentuan nilai estimasi stok karbon melalui biomassa yang memanfaatkan sistem informasi geografi dan citra satelit Landsat 8 berbeda dengan penentuan yang dilakukan dengan memanfaatkan informasi kandungan biomassa dengan pengukuran diameter batang. Penentuan nilai estimasi menggunakan citra satelit dapat dilakukan dimana saja tanpa perlu mendatangi langsung daerah yang ingin diteliti dan hanya membutuhkan kelengkapan bahan olahan data saja. Nilai estimasi potensi biomassa yang akan digunakan untuk menduga nilai stok karbon didapat dengan persamaan hasil regresi masing-masing Band pada citra satelit Landsat 8 untuk kawasan mangrove di Sungai Tallo Makassar.

Berdasarkan penelitian yang dilakukan oleh Rahman dan Rusmana 2017, pada dua tahun yang lalu mengenai pendugaan nilai stok karbon menggunakan persamaan alometrik dengan pengukuran yang dilakukan dengan metode acak (mempertimbangan keterwakilan berdasarkan kerapatan mangrove) didapat lah nilai dari biomassa dan estimasi stok karbon dari mangrove di daerah dekat jembatan Sungai Tallo hingga Pulau Lakkang sebagai literatur. Rahman dan Rusmana (2017) mendapatkan nilai biomassa berdasarkan luas aera tumbuh dan tingkat kepadatan mangrove, dengan nilai total biomassa maksimum dari jenis mangrove $N$. fruiticans, $R$. mucronata, dan A. alba sebesar 151.1 ton/ha dan minimumnya 43.38 ton/ha dengan estimasi nilai stok karbon maksimumnya sebesar 71.96 ton/ha dan minimumnya 19.96. Hasil ini berbeda dengan nilai estimasi biomassa yang didapat dengan olahan band 6 citra satelit Landsat 8 dengan nilai panjang gelombang antara 1.57-1.65 $(\mu \mathrm{m})$ (Sitoms, 2004) yang memiliki nilai biomassa maksimum sebesar 1115.40 ton/ha dan nilai minimummya sebesar 168.65 ton/ha seperti pada gambar 3. Berdasarkan nilai biomassa yang didapat itu nilai estimasi dari stok karbon dapat diketahui dengan mengambil $46 \%$ dari hasil biomassa yang didapat, sehingga didapatlah nilai estimasi stok karbon maksimumnya sebesar 513.08 ton/ha dan minimumnya sebesar 77.57 ton/ha.

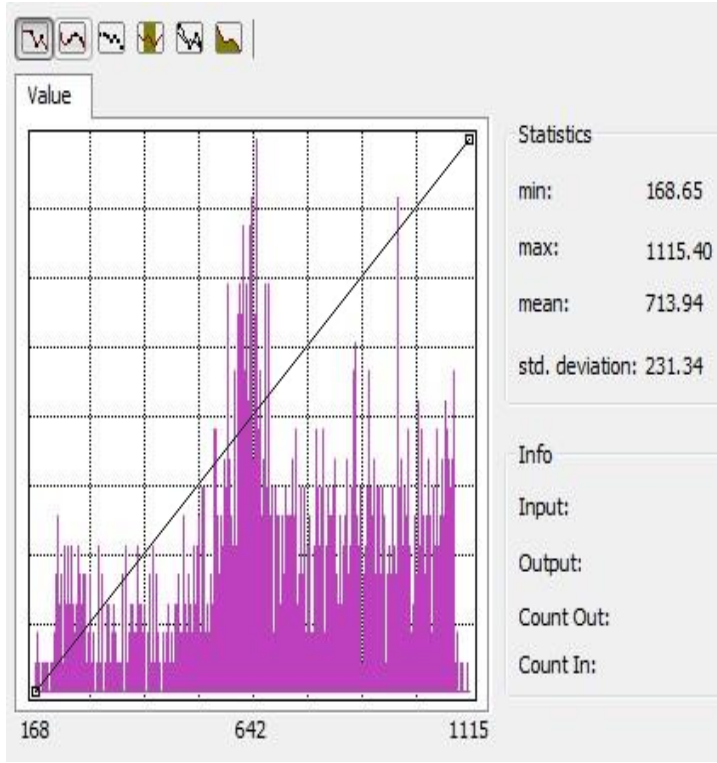

Gambar 2. Histogram nilai estimasi biomassa tanaman mangrove di Sungai Tallo Makassar.

Sumber : Aplikasi ArcGIS 10.3

Berdasarkan penjelasan mengenai nilai biomassa pada gambar 2 dan stok karbon sebelumnya terlihat nilai dari masing-masing biomassa dan stok karbon yang didapat berbeda dengan literature yang didapat oleh Rahman dan Rusmana (2017) melalui pengamatan secara langsung. Penyebab perbedaan ini dikarenakan penelitian yang dilakukan oleh Rahman dan Rusmana (2017) menghitung estimasi biomassa dan karbon permasing-masing jenis tanaman dengan indikator yang ada ditanaman mangrove seperti luas daun, rata-rata diameter pangkal hingga pelepah yang hubungannya dengan nilai biomassa. Sedangkan nilai biomassa 
yang diperoleh menggunakan citra satelit band 6 itu mengambil wilayah dimana mangrove itu berada. Cara ini mempunyai kelemahan dikarenakan band 6 memiliki karakterisitik peka terhadap air yang dimana semakin kecil energi yang dipantulkan oleh band 6 mengindikasikan semakin banyak energi yang diserap oleh badan air. Akibatnya hasil dari nilai biomassa yang didapat begitu besar dikarenakan diwilayah kajian banyak sekali terdapat badan air yang berada di sekitar tanaman mangrove itu sehingga mempengaruhi hasil dari nilai biomassa dan estimasi stok karbonnya.

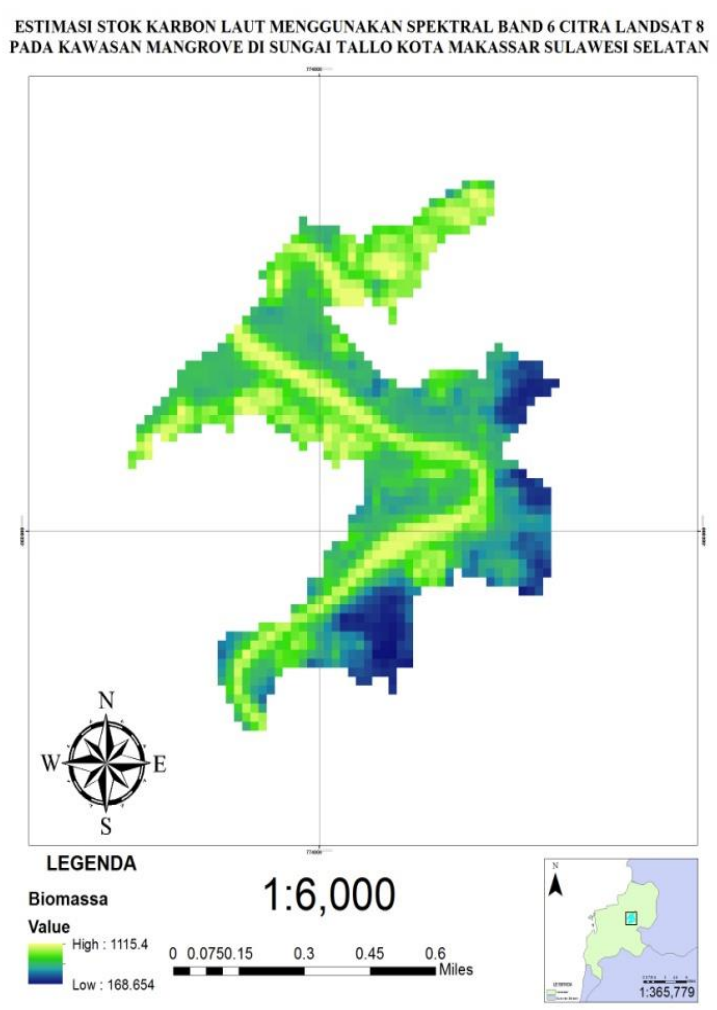

Gambar 3. Peta sebaran estimasi nilai biomassa tanaman mangrove di Sungai Tallo Makassar.

Sumber : Aplikasi ArcGIS 10.3

Kemudian berdasarkan gambar 3 diatas terlihat pengelompokkan nilai biomassa yang berada di kawasan mangrove itu didasari oleh klasifikasi warna yang ada. Peta tersebut merupakan hasil deliniasi dari kawasan mangrove di Sungai Tallo di Kota Makassar dengan skala 1 berbanding 6000. Berdasarkan gambar tersebut nilai biomassa yang didapat ditunjukkan dengan warna biru hingga kuning yang dimana jika warna yang terlihat semakin menuju warna kuning maka nilai energi yang dipancarkan oleh band 6 semakin tinggi untuk menunjukkan nilai biomassanya dan semakin kearah biru akan semakin kecil. Lokasi mangrove yang diteliti berada di sekitaran Sungai Tallo dan cenderung pancaran energi yang dipantulkan semakin kecil ke arah sungai yang artinya semakin banyak energi yang diserap oleh badan air.

\section{KESIMPULAN}

Hasil olahan citra satelit Landsat 8 menggunakan band 6 pada software Arcmap 10.3 menunjukkan nilai dari biomassa maksimum kawasan mangrove di Sungai Tallo sebesar 1115.40 ton/ha dan minimumnya sebesar 168.65 ton/ha dengan nilai stok karbon selanjutnya bisa didapatkan dengan mengambil $46 \%$ dari nilai biomassanya sehingga didapat estimasi nilai stok karbon maksimal nya sebesar 513.08 ton/ha dan minimumnya sebesar 77.57 ton/ha. Nilai biomassa dan stok karbon yang didapat mengalami perbedaan dibandingkan perhitungan literatur yang menggunakan rumus alometri dan pengamatan langsung berdasarkan nilai massa jenis, diameter pohon ataupun ketinggiannya pada tahun 2017 yang hanya memperoleh biomassa maksimum sebesar 153.1 ton/ha dan minimumnya sebesar 43.38 ton/ha dengan masing-masing nilai stok karbon yang didapat hanya berkisar pada 71.96 ton/ha untuk nilai maksimumnya dan 19.96 ton/ha untuk nilai minimumnya akibat karakteristik sifat dari band 6 yang terlalu peka terhadap badan air pada tutupan lahan sehingga memengaruhi hasil perhitungan biomassa nya.

\section{DAFTAR PUSTAKA}

Badan Pusat Statistik. 2018. Kota Makassar Dalam Angka 2018. Makassar(ID): BPS Kota Makassar, p.403.

Beddu, S., 2011. Bantaran Sungai Sebagai Konservasi Lansekap Alami (Studi Kasus: Bantaran Sungai Tallo Makassar), Jurnal Teknik Lingkungan, Vol.5, no.1 pp 1-7.

Donato, D. C. Kauffman, J. B. Murdiyarso, D. Kurnianto, S. Stidham, M. dan Kanninen, M., 2012. Mangrove Salah 
Satu Hutan Terkaya Karbon di Daerah Tropis, Brief CIFOR, Vol. 12, no.1 pp 1-12.

Fromard F, Puig H, Mougin E, Betoulle JL, Cadamuro L. 1998. Structure, aboveground biomass and dynamics of mangrove ecosystems: new data from French Guiana, Oecologia, Vol.115, no.1 pp 39-53.

Hairiah, K. dan Rahayu, S., 2007. Pengukuran 'Karbon Tersimpan' di Berbagai Macam Penggunaan Lahan. Bogor (ID) : World Agroforestry Centre ICRAF, SEA Regional Office, p.21.

Komiyama, A. Ong, J. E. Poungparn, S., 2005. Allometry, biomass and productivity of mangrove forest: A review, Aquatic Botany, Vol.89, no.1 pp 128-137.

Nasprianto. Desy, M. H. M. Terry, L. K. Restu, N. A. A. dan Andreas, H., 2016. Distribusi Karbon di Beberapa Perairan Sulawesi Utara, Jurnal Manusia dan Lingkungan, Vol.23, no.1 pp 34-41.

Rahman. Effendi, H. Rusmana, I., 2017. Estimasi Stok dan Serapan Karbon Pada Mangrove di Sungai Tallo Makassar, Jurnal Ilmu Kehutanan, Vol. 11, no.1 pp 19-28.

Sitoms, J., 2004. Pengembangan Model Estimasi Umur Tanaman Kelapa
Sawit Dengan Menggunakan Data Landsat-TM, Jurnal Penginderaan Jauh dan Pengolahan Citra Digital, Vol.1, no.1 pp 14-19.

Supriharyono., 2000. Pelestarian dan Pengelolaan Sumber Daya Alam Wilayah Pesisir Tropis. Jakarta(ID): Gramedia, p.158.

Supriharyono, 2007. Konservasi Ekosistem Sumberdaya Hayati di Wilayah Pesisir dan Laut Tropis. Yogyakarta(ID): Pustaka Pelajar, p.428.

Sutaryo, D., 2009. Penghitungan Biomassa, Sebuah Pengantar untuk Studi Karbon dan Perdagangan Karbon. Bogor(ID): Wetlands International Indonesian Programme, p.39.

Utomo, P. D., 2015. Analisis spektral citra landsat 8 untuk menduga simpanan karbon biomassa di ekosistem lahan kering agroforestri (studi kasus : Tamiyang Layang, Kalimantan Tengah). Skripsi. Fakultas Matematika dan Ilmu Pengetahuan Alam. Bogor(ID) : Institut Pertanian Bogor. 